\title{
Espaços em volta: percursos imaginantes em L'horizon de Patrick Modiano e A Amante Holandesa de J. Rentes de Carvalho
}

\author{
Maria João Simões \\ Universidade de Coimbra - CLP
}

\begin{abstract}
Resumo: A disposição e a arquitetura dos espaços nos textos literários são elementos cruciais para a construção da imagética espacial em termos culturais. Ao defender a relevância da geocrítica literária, Bertrand Westphal afirma que ela deverá ir além do estudo das representações do espaço em literatura, sendo necessário considerar como seu objeto o exame das interações entre espaços humanos e literatura. Salienta ainda que, se as representações do 'outro' são essenciais para a construção de autoimagens, para a determinação/indeterminação das identidades culturais, será imprescindível estudar os modos de viver e conceber o espaço. 0 estudo a desenvolver neste trabalho partirá dos pressupostos teóricos aludidos e terá como principais objetivos a compreensão do jogo entre a topofobia ou a topofilia em J. Rentes de Carvalho (principalmente na obra A Amante Holandesa) e a interpretação dos sentidos da topofilia urbana em Patrick Modiano (sobretudo em L'horizon). A observação dos diferentes modos de tratamento ficcional do espaço e a análise das diferenças e das analogias entre as perspetivas acionadas pelos dois autores permitirão explorar a complexidade do potencial imaginante que o espaço detém na literatura.
\end{abstract}

Palavras-chave: Topoanális e, Ambiente, Imagologia, Rentes de Carvalho, Patrick Modiano

Abstract: The disposition and architecture of spaces in literary texts are crucial elements for the construction of spatial imagery of cultural life. Bertrand Westphal advocates for the relevance of literary geocriticism, which according to the author should transcend the study of "how space is represented in literature" and examine "the interactions between human spaces and literature". Westphal additionally states that if we consider how "the other" is represented to be crucial for the construction of self-images, then the study of the 
ways in which space is conceived and inhabited/lived in is fundamental for "the determination/indetermination of cultural identities". The following work is based on the aforementioned theoretical principles, and its main goals will be to understand the interaction between topophobia and topophilia in the work of J. Rentes de Carvalho (mainly in A Amante Holandesa), and to interpret the meaning(s) of urban topophilia in the work of Patrick Modiano (mainly in L'horizon). Focusing on the different ways in which space is fictionally approached and on the analysis of both the differences and the analogies between the perspectives that are set in motion by both authors, we will aim to explore the complexity of the imaginative potential of space in literature.

Keywords: Topoanalys is, Setting, Imagology, Rentes de Carvalho, Patrick Modiano

A captura é, segundo Fernando Gil, uma das metáforas da evidência, cujo étimo radica numa perceção que se diz e se mostra. Assim, a evidência "é da família de vidência" (Gil 1996: 84). Ora, o espaço liga-se à evidência na medida em que os dois têm em comum a matriz da perceção sobretudo visual - mas não, obviamente, apenas visual. Assim, captar o espaço é uma forma de colher um "instantâneo", tal como a fotografia é uma forma de agarrar o instante.

A este propósito diz Jean-Luc Nancy:

Instantâneo: foto, um espaço de tempo exposto. Aqui, o tempo é ele mesmo espaço. [...] 0 instante não é tempo: mas tópica, topografia, circunstância, circunscrição de um agenciamento particular dos lugares, aberturas, passagens. (Nancy 2008: 95)

Poder-se-á interpretar a intenção compulsiva de captar o instante do lugar que se verifica no homem atual, constantemente fotografando o lugar e autofotografando -se no lugar, como uma necessidade de captar o lugar do instante que lhe foge sempre e como um modo de escapar ao que o filósofo designa por "barbárie do tempo"? Estas são perguntas que nos devolvem uma obrigação de atentar no espaço e no seu significado.

Ainda segundo o filósofo francês, "o espaço não está contra o tempo, senão para libertar o 
tempo, a vinda, a ida-e-vinda, para lhe dar acolhimento espacioso" (ibidem). Este acolhimento espacioso espraia-se nesse "agenciamento particular dos lugares, aberturas, passagens" (ibidem).

Nas palavras deste pensador da contemporaneidade, ganha relevo a ideia de "agenciamento", porque ela ecoa a expressão "agenciamento de factos" com a qual se tenta traduzir a expressão (ela própria já traduzida) "rerum compositio”,1 utilizada por Aristóteles na Poética, quando fala da intriga na tragédia. Neste sentido, falar de "agenciamento de lugares" implica pensar que o espaço é construído, arranjado, disposto de várias formas, concorrendo assim para a composição das ficções literárias entendidas como construtos ficcionais.

É certo que a ideia de comparticipação do espaço na construção ficcional não é uma novidade. 0 que surge de novo é a consideração do espaço para além do seu sentido decorativo ou de mero cenário e para além do sentido que carreia em termos de contextualização social.

Várias abordagens têm sido propostas, como refere Marie-Laure Ryan na entrada sobre "espaço" em The Living Handbook of Narratology, onde a autora, para a análise mais detalhada do espaço, propõe as seguintes distinções:

Molduras espaciais;

Ambiente ou ambientação (setting);

Espaço da história (cenário do enredo talvez possa ser uma tradução adequada - mapeando ações e pensamentos das personagens );

Mundo narrativo (envolvendo a imaginação do leitor);

Universo narrativo (envolvendo crenças, medos e ideologia das personagens). (Ryan 2014: 6-10)

Pretende-se aqui prestar uma atenção maior à noção de "ambiente" que se propõe como equivalente a setting (uma equivalência que pode ser discutível e que não encerra a questão da tradução da palavra).

Aproximam-se das destrinças apresentadas por Marie-Laure Ryan aquelas propostas por Ozíris Borges Filho na sua obra Espaço \& Literatura - Uma Introdução à Topoanálise, 
onde o autor distingue: cenário, natureza, ambiente e paisagem (para além de fazer a distinção entre macroespaços e microespaços). Mais especificamente, no que diz respeito ao ambiente, o autor propõe a seguinte definição:

\footnotetext{
D] efine-se ambiente como a soma de cenário ou natureza mais a impregnação de um clima psicológico. Esquematicamente, teríamos:

1. - Cenário + clima psicológico = ambiente;

2. Natureza + clima psicológico $=$ ambiente. (Borges Filho 2007: 50)
}

Estas e outras distinções ensaiam uma análise mais afunilada do espaço. Caminha neste sentido também a abordagem de James Phelan e Peter Rabinowitz, na obra Narrative Theory: Core Concepts and Critical Debates, uma vez que os autores procuram, num nível mais pormenorizado, estabelecer distinções relativamente ao modo como pode ser ficcionalizado o ambiente ou a ambientação — "setting" no original:

\begin{abstract}
Given our pragmatic orientation our aim is [...] to determine the rhetorical function of setting in narrative, or, more accurately, the variety of functions possible for setting within narrative. Fundamentally, setting, like character, has three components: the synthetic, the mimetic and the thematic, any or all of which can take on important functions in a given narrative - depending on the nature of the narrative's progression and purpose". [0 nosso objetivo é determinar a função retórica da ambientação na narrativa, ou, mais precisamente, a variedade de funções possíveis para a ambientação. Fundamentalmente, a ambientação, como a personagem, tem três componentes: sintética, mimética e temática, todas (e cada qual) delas podem desempenhar uma importante função na narrativa.] (Phelan \& Rabinowitz 2012: 85)
\end{abstract}

Facilmente se deduz o significado das componentes mimética e temática da ambientação. Diferente destas, a componente sintética ou formal caracteriza-se, segundo os autores, por ser "contrastiva" e "diacrítica", podendo dizer-se que se trata do modo como a ambientação desencadeia um enquadramento espacial diferenciado e diferenciador de uma ficção para outra ficção, ou de uma narrativa para outra.

De modo bem diverso, quer Patrick Modiano, quer Rentes de Carvalho, logo nas primeiras páginas das suas ficções, estabelecem uma ambientação específica. 
Na obra L'horizon, há um sentido contrastivo e diferenciador logo no jogo com o título, cujo sentido paisagístico choca com o ambiente citadino da obra, uma vez que as personagens e a intriga são colocados, desde o início, no centro de Paris e mais especificamente na Rue du Quatre-Septembre, ou seja, bem perto de uma das artérias principais da capital - a Avenue de l’Opéra. Na verdade, o leitor terá de se adentrar bem mais longe na narrativa para poder decodificar a que horizonte se refere o título. Acompanhando as personagens, o leitor deverá mergulhar no espaço da grande metrópole, dado a ver/ler pelas inúmeras referências a ruas, estações de metro e bairros parisienses. Jean Bosman, o protagonista, trabalha numa livraria perto do Parc Montsouris e repetidamente vai buscar Margaret à saída do trabalho na Rue du Quatre-Septembre, para a acompanhar até ao seu quarto em Auteuil. Há descrições, mas estas são breves e rápidas, servindo mais para estabelecer o enquadramento ambiental do que para representar minuciosamente o espaço. Neste tratamento do espaço, sobressai menos a sua função mimética e muito mais a sua função sintética, diacrítica, discriminativa. Por exemplo, verifica-se um maior interesse em dar uma ideia rápida acerca do tipo de imóvel onde trabalha Margaret le Coz do que propriamente o de descrever, de forma minuciosa, o local - conseguindo assim transmitir a ideia de que se trata de um escritório num prédio com muitos outros escritórios e de um edifício igual a tantos outros. 0 que é mais importante é situar o primeiro encontro entre Jean Bosman e Margaret le Coz, uma vez que o par se conhece por acaso nessa rua. Conhecem-se por serem apanhados, sem querer, num confronto entre manifestantes e as forças policiais CRS (Compagnies républicaines de sécurité). Esta confrontação faz fugir os protestantes, que se atropelam nas escadas do metro, e, deste modo, arrastam as duas personagens Jean Bosman e Margueret le Coz, lançando-as um contra o outro (Modiano 2010: 13).

Para prosseguir a abordagem das obras, vale a pena cruzar as três distinções acima referidas - as componentes sintética, mimética e temática - com a proposta feita por Marie-Laure Ryan, Kenneth Foote e Maoz Azaryahu em Narrating Space / Spatializing Narrative, onde os autores distinguem "espaço emocional" de "espaço estratégico", explicando esta dicotomia da seguinte forma: 
[There are] two contrasting relations that play a major role in shaping narrative content: emotional and strategic. In the emotional relation, spatial objects matter for what experiences they afford, for what aesthetic feelings they inspire, and for what memories they bring to mind. [...] Since emotional space involves a lived, embodied experience, it is best represented by pictures taken from a horizontal perspective (...). While emotional space typically takes form of an appealing or frightening landscape, strategic space is best symbolized by chessboard. [...] Strategic space is best represented in map view as a vertical projection in which no object hides any other". [Há] duas relações contrastantes que têm um papel determinante na construção do conteúdo narrativo: emocional e estratégico. Na relação emocional, os objetos espaciais são relevantes devido às experiências que proporcionam, aos sentimentos estéticos que inspiram, e às memórias que trazem à mente (evocam). [...] Como os espaços emocionais envolvem experiências vividas e corporizadas, são mais bem representados por imagens obtidas numa perspetiva horizontal [...]. Enquanto o espaço emocional toma a forma, tipicamente, de uma paisagem agradável ou assustadora, o espaço estratégico é mais perfeitamente representado por um tabuleiro de xadrez. [...] 0 espaço estratégico é mais bem representado como um mapa, como uma projecção vertical em que nenhum objecto esconde qualquer outro.] (Ryan et al. 2016: 39)

Voltando à obra de Modiano, verificamos que, no enquadramento ambiental construído inicialmente no romance, parece ressumar mais um espaço sintético e de emoção reduzida, um espaço geral de encruzilhadas e de linhas por onde as personagens circulam como títeres de uma época vagamente apresentada - apenas escassas referências (como aquela que é feita sobre as forças de segurança CRS) sugerem tratar-se do tempo de pós-guerra, nos anos 50 e 60. Aliás, acentua-se o facto de as personagens decidirem optar por lugares temporários (como, por exemplo, hotéis), de mudarem muito de "poiso", e de escolherem quartos em lugares pacíficos, aproveitando o sentido labiríntico da grande cidade para fugir de conhecidos e para tentar não deixar traços ou vestígios que permitam reencontros indesejáveis.

Diferentemente, em A Amante Holandesa, o enquadramento ambiental é emocionalmente estruturado de forma dicotómica: a aldeia nas serranias ou a cidade, o "cá" ou o "lá", sendo o "cá" a terra natal ("estes lados") e o "lá" o país estrangeiro — "Lá é diferente. [...] Lá, é na Holanda" (Carvalho 2016: 10, 28). A esta dicotomia liga-se um diferencial de tempo: o passado e o presente das personagens. Como é de esperar, não 
deixam de estar presentes elementos sintéticos estruturantes do ambiente (setting), como é o caso da referência à Linha do Sabor e à estrada de Bragança para a aldeia. Porém, aqui, a função mimética predomina sobre a função sintética, uma vez que as descrições abundam e são precisas e longas. Ora, esta função mimética, como afirmam Phelan e Rabinowitz (2012: 86), é desvalorizada pelos detratores do descritivo, que consideram a descrição meramente orientada em função da tematização e da simbologia do espaço, sem atender ao prazer de ler a descrição que Rentes de Carvalho explora e preserva:

Por estes lados o viajante só vê montes. Desertos, amarelados, pedregosos, às vezes com uma ermida no alto, outros coroados de pinhos. Nalgumas encostas os sulcos de um campo lavrado. Aqui e além bocados de vinha, [...] aldeias tão longínquas que são apenas manchas brancas na paisagem.

Os atalhos velhos, abandonados, encheram -se de mato. Vai-se agora pela estrada, ou corta-se nos caminhos abertos nos baldios pelos tractores da câmara. Da linha do comboio de via estreita, abandonada, ficaram os carris a marcar a presença [...]. 0 apeadeiro desapareceu [...], mas [...] deixaram as placas que avisavam do perigo [...]. "Pare, escute e olhe" [...]. Precaução [...] absurda [...] pois por dia passavam ali apenas dois comboios: o que "subia" até Duas Igrejas e o que "descia" até ao Pocinho, onde entroncava com a linha do Douro. (Carvalho 2016: 11-12)

Obviamente, neste pendor descritivo transparece o modo como as emoções interferem na forma como é representado o espaço, fazendo emergir o que os autores de Narrating Space / Spatializing Narrative designam por "emotional space", que neste caso não é assustador, mas sim atraente e semeado de notas nostálgicas (cf. Ryan et al. 2016: 3040).

Estas diferentes formas de observação dos elementos espaciais colocam em evidência a importância do espaço na estratificação e composição da obra literária, que, já desde a década de 60 do século XX, tin ha sido salientada por Roman Ingarden, ao apontar as "condições espaciais do mundo objetivo apresentado":

Quando numa obra de arte se apresentam coisas, animais e homens, o espaço que ao mesmo tempo com eles se apresenta não é o espaço abstrato, geométrico ou físico e homogéneo, mas sim aquele que corresponde ao espaço dado na perceção. Neste caso ele deve, por assim dizer, ser exposto através do meio do espaço de orientação. Devem empregar-se nisto especialmente espaços de orientação 
pertencentes aos sujeitos psíquicos apresentados que "percecionam" este espaço apresentado. (Ingarden 1979: 252)

Roman Ingarden fala de orientação relativamente aos espaços que são percecionados pelas personagens e pelos narradores. Ou seja, não é só o espaço representado, é o espaço como é representado, tendo em conta a perspetiva das personagens e dos narradores. A perspetiva é, assim, um elemento fundamental para analisar o espaço.

Se cruzarmos esta ideia com as destrinças teóricas de Phelan / Rabinowitz e com as de Marie-Laure Ryan (acima referidas), poder-se-á observar como a ideia de espaço emocional está obviamente ligada à perspetiva valorativa ou deprecia tiva das personagens e dos narradores. Poder-se-á ainda pensar que a componente mimética do espaço pode ter maior ou menor amplitude consoante a perspetiva adotada, que, por sua vez, pode ser mais ou menos confiável. Trata-se de considerar aqui o sentido de mediação implicado no conceito de perspetiva, de acordo com o entendimento de Peter Hühn, Wolf Schmid e Jörg Schönert, na obra Point of View, Perspective, and Focalization: Modeling Mediation in Narrative. Na introdução, Peter Hühn esclarece qual o intuito da obra:

The aim is to explore the great variety of sensory, cognitive, ideological, semiotic and technical modalities of transmitting, representing and structuring happenings in narrative communication. Special emphasis is given to the notion of mediation as a basis for analysis and comparison of these various modalities with respect to the constitution and constellation of mediating instances, but also to the influence of social and cultural contexts and technological conditions on mediation. [0 objetivo da obra é explorar as modalidades de transmitir, representar e estruturar os acontecimentos na comunicação narrativa na sua grande variedade sensorial, cognitiva, ideológica, semiótica e técnica. É dada uma enfâse especial à noção de mediação como base para a análise e comparação destas diversas modalidades respeitantes à constituição e orquestração das instâncias de mediação, mas também à influência dos contextos socioculturais e às condições tecnológicas da mediação.] [Hühn et al. 2009: 8)

Um dos eixos de estruturação do espaço depende, pois, do modo como ele é perspetivado pelos narradores e também pelas personagens, tornando o espaço motivado. 
Assim, as personagens de L'horizon rodam e rondam² pelas ruas da cidade, procurando sentir-se seguros no anonimato da grande metrópole para fugir de conhecidos ou para criar ancoragens apenas temporárias, o que é representado metonimicamente no hábito que Margaret ganhara de dobrar e preparar sempre a roupa, para o caso de ter de fugir durante a noite ou de madrugada.

Por seu turno, na obra A Amante Holandesa, também é notório que o espaço é dado a ver de modo emocionalmente carregado pelo narrador e pelas personagens. A título de exemplo, pode referir-se o modo como o Gato (alcunha por que era conhecido Amadeu), amigo de infância do narrador, perceciona o espaço do "lá", o espaço do "estrangeiro":

— Então, conta lá. Porque é que a Holanda é diferente? [...]

— Nós aqui só temos terra e mais terra. Calhaus. Lá é tudo água. Água que nunca acaba. Ele são canais e rios, ribeiros, lagos... No princípio custou-me a habituar. Quando passava por um canal dizia comigo: este é o último. Qual quê! Na rua adiante havia logo outro. (Carvalho 2016: 29)

Apesar de sobressair, nesta obra, a componente mimética do espaço enunciada por Phelan e Rabinowitz, torna-se evidente que o espaço emocional se estende para além dela, atingindo também a componente temática, a qual, se se atentar na explicação das suas características feita pelos autores, corresponde, pelo menos em parte, àquilo que frequentemente se designa por função simbólica do espaço.

Uma vez chegados aqui, é premente fazer duas observações:

1. a Há, na explicação desta tríade analítica do espaço - sintética, mimética e temática - uma oscilação conceptual entre componente e função, oscilação que possivelmente advém da impossibilidade de separar, de modo estanque, estas camadas de significação espacial.

2. a 0 espaço emocional infiltra-se nas várias componentes espaciais, confirmando assim o esquema proposto por Ozíris Borges Filho:

Cenário + clima psicológico = ambiente;

Natureza + clima psicológico $=$ ambiente .

Por sobre tudo isto, é ainda indispensável pensar que alguns destes aspetos, em 
certa medida, são ainda considerados de forma unidirecional e de sentido único e, hoje, o paradigma de compreensão e de entendimento é mais complexo - é um paradigma relacional, onde predomina a metáfora da rede, a qual, como sabemos, impregna o nosso pensamento e a nossa vida.

É neste sentido relacional que se compreende a interrogação de Bertrand Westphal, no texto intitulado "Por uma abordagem geocrítica dos textos — Esboço":

... não é tempo de pensar em articular a literatura em torno de suas relações com o espaço, de promover uma geocrítica poética cujo objeto seria não o exame das representações do espaço em literatura, mas o das interações entre espaços humanos e literatura, de que uma das maiores apostas seria uma contribuição à determinação/indeterminação das identidades culturais? (Westphal 2016: 219).

Ao falar em interações entre espaços humanos e literatura, Bertrand Westphal revela essa preocupação relacional, sendo credível que o crítico não rejeite ter uma matriz relacional como fundamento da sua teorização.

Neste sentido relacional, o espaço pode ser analisado sob várias lentes e de vários ângulos, tendo em conta também interferências e interseções múltiplas dentro da própria construção ficcional. Assim, do ponto de vista interno, para além da estreita ligação à perspetiva das personagens, ao tempo (bem evidenciada na noção bakhtiniana de cronótopo) e aos narradores, há a considerar ainda que o espaço está intrinsecamente ligado à intriga e ao seu ethos, que pode ser sublime, grotesco, fantástico, cómico, etc., ou seja, é determinado e marcado pela predominância de um entre os vários predicados estéticos explorados pela obra.

As duas obras selecionadas, por serem obras de características diversas, permitem observar diferenças e variantes no concernente a esta conexão entre espaço e intriga.

$\mathrm{Na}$ intriga de L'horizon, o protagonista Bosman (ao qual o narrador se cola intimamente) estabelece uma relação muito próxima com o espaço, quando tenta recuperar, num constante exercício de memória, eventos da sua vivência nos anos 60 e da sua relação com Margaret le Coz. Na verdade, esta rememoração topofílica constitui móbil 
construtor da intriga - uma intriga vaga e fluida que se ganha alguma densidade é precisamente através da concretude topográfica. Ele procura pormenores capazes de desencadear a lembrança: "uma data, um local preciso, um nome” 3 (Modiano 2010: 7). Para ele, os nomes próprios ou os apelidos "serviam de ímanes. Traziam à superfície impressões confusas difíceis de esclarecer" (idem, 8). Ora, uma das funções importantes dos espaços é precisamente a de potenciarem as recordações ${ }^{4}$ e permitirem recortar acontecimentos da frágil e lábil intriga que é, assim, reconstruída, quase detetivescamente, dispondo as figuras nos espaços e reconfigurando os seus "passos em volta" e as suas deambulações.

Simbolicamente, a cidade de Paris, com os seus diferentes bairros, ruas e cruzamentos, permite fugas e encontros e lança possibilidades, mostrando como o espaço é parte agente na invenção e no agenciamento da intriga - como o seguinte exemplo pode ilustrar:

Preferia não sair daquele bairro. Parecia-lhe atingir uma encruzilhada a sua vida, ou antes uma orla da qual poderia dar um salto para o futuro. Pela primeira vez, acudia-lhe à ideia uma palavra: futuro, e outra palavra: horizonte. Naquelas noites, as ruas desertas e silenciosas do bairro eram linhas de fuga que, todas elas, conduziam ao futuro e ao HORIZONTE." (Modiano 2010: 54)

Do ponto de vista temático-simbólico, a intriga da obra de Rentes de Carvalho, a um primeiro olhar, parece organizar-se em contraposições, como acima se referiu: os montes severos e as aldeias pobres de Trás-os-Montes e Alto Douro, contrastando com Amesterdão, ou a cidade de Bragança, contrastando com a aldeia. Mas estas relações opositivas complexificam-se nos múltiplos cruzamentos das perspetivas das diversas personagens. Se de facto o Gato, para fugir à pobreza, emigrou, a Holanda não foi para ele o El Dorado desejado, pois não lhe permitiu seguir o seu sonho de ser carteiro - "lá" conseguiu apenas ser estivador. Na verdade, este sonho vem do tempo em que o ágil pequeno Amadeu conseguia, acrobaticamente, receber e entregar os sacos de correio com o comboio em andamento - feito que lhe valeu a alcunha de o Gato. Orgulhoso do que fazia, o Gato ambicionava tornar-se carteiro, vendo-se impedido de o ser pelo facto de ser analfabeto. Mas este impedimento tanto acontece em Portugal como na Holanda, quebrando-se assim o 
sentido dicotómico. Por sua vez, quando Laura, a filha que deixou na Holanda, vem à terra do pai, depois da sua morte, o seu intuito é mais o de situar pitorescamente a história que lhe contaram sobre o pai do que realmente procurar entender as raízes dele, sendo incapaz, por diferenças geracionais e culturais, de compreender a pobreza por ele vivida.

O que está em causa nestas perceções ficcionalizadas é o cruzamento de diferentes tipos de relações de pertença identitária espacial, numa escala que vai de um olhar "de dentro" (e uma sensação de acolhimento) a um olhar "de fora" (e um sentimento de estranheza). É aqui (entre outros pontos) onde a geocrítica interseta a imagologia. Sobre esta interseção, Bertrand Westphal tem uma opinião algo negativa, sendo possível ler o seu posicionamento nas seguintes afirmações:

A abordagem imagológica ${ }^{5}$ é [...] adotada [...] em todos os que colocam em relação uma cultura que olha [...] e uma cultura olhada, as duas separadas por uma distância diferencial que será captada em uma representação [...] estereotipada [...]. A questão é saber se a imagologia está apta a levar em conta [...] o estudo dos espaços na sua globalidade.

Claro que não. Para dizer a verdade, essa missão nunca foi designada à imagologia. Nela o Outro é invariavelmente outro em um mundo caracterizado [...] por uma oposição entre [...] identidade e contradição. A imagologia dedica um espaço de coexistência entre duas ou mais entidades, mas em nenhum momento um espaço de confusão. [...]

Adotando o ponto de vista geocrítico, adotamos necessariamente um ponto de vista plural, que se situa no cruzamento das representações autóctones e alógenas ${ }^{6}$. [...]. Por aí tocaríamos mais de perto a verdadeira essência identitária do espaço estudado, [...] confirma(ndo) que toda a identidade cultural $^{7}$ [...] é plural; toda a identidade é arquipélago. (Westphal 2016: 214, 234)

Tem inteira razão Bertrand Westphal em dizer que não cabe à imagologia o estudo dos espaços na sua globalidade, porque, como o pensador afirma, o seu objetivo não é esse. Porém, a imagologia também deve estudar - e estuda - casos de interseção cultural, de hibridismo: estuda os mais variados graus e tipos de interferência cultural, desde a alofilia mais maníaca à xenofobia mais disfarçada.

Como exemplo, poderemos pensar nas subtis e muitas vezes implícitas reações de estranhamento suscitadas pela personagem de Margaret le Coz, da qual se diz ter nascido 
na Bretanha, ter vivido em Berlim, vivendo depois em Annecy (na Haute-Savoie), de onde foge para Lausanne, e fugindo daí, por seu turno, para Paris, de onde também terá fugir mais tarde. 0 seu sinuoso percurso mais a sua situação de desenraizamento e de solidão geram a incompreensão de muitos dos que as rodeiam e sobretudo tornam-na vulnerável ao menosprezo e mesmo à perseguição obsessiva da personagem sinistra que é Boyaval.

Pensando nesta personagem e neste romance, se se utilizar, teor eticamente, um cruzamento da abordagem geocrítica com a abordagem imagológica, esclarecem-se melhor as zonas obscuras deste romance, cujo ambiente é tão especificamente "modianesco". Para abordar este romance, onde o espaço tem grande destaque, é obviamente útil a topoanálise e a geocrítica; mas também é importante inteligir o sentido simbólico do desenraizamento das suas personagens, que traz ao romance um ethos de perda identitária e de nostalgia que talvez uma abordagem imagológica ajude a perceber melhor. Com efeito, o percurso errático das duas personagens torna isto bem percetível.

Quanto ao romance $A$ Amante Holandesa, todas as superficiais dicotomias se complexificam com a vinda de Laura, filha do Gato, que, com a sua liberdade geracional e cultural, vem contar uma outra versão da história inicialmente contada pelo próprio Gato dos seus amores com uma holandesa, mãe desta sua filha. Esta nova versão contraria a anterior, desmistificando-a, roubando-lhe o lirismo idílico, pondo a nu a falta de integração de Amadeu, o Gato, no período por ele vivido na Holanda, ao contrário do que ele próprio apregoara. Isso obriga o narrador a rever toda a história que julgava saber e, com ele, também o leitor deverá reavaliar também a história e as dores deste emigrante que, como qualquer emigrante, teve dificuldade em se ambientar no espaço para onde foi, que regressa inevitavelmente diferente e que vai carregar essa diferença para o resto da sua vida, alterando inevitavelmente, depois de regressar, a sua autorrepresentação e a sua autognose.

Nesta obra, o autor conseguiu representar esse hibridismo identitário que vem do choque de culturas vivido e sentido, a partir de um peculiar agenciamento da relação espaçointriga. Não deixa por isso de surpreender, negativamente, e de serem lidas como contraditórias, recentes tomadas de posição ideológicas, políticas e sociais do autor, 
desvalorizadoras de hibridismos e intercâmbios culturais — hibridismos e intercâmbios que existem desde que o mundo é transformado pelo homem e que felizmente continuarão a existir.

Fica patente, através das abordagens realizadas sobre o jogo dos espaços nestas ficções, o modo como as identidades culturais se vão construindo no e pelo espaço. Tanto a encenação do deambular pela cidade ou pelos campos como a captura orquestrada das imagens vistas pelas personagens na infância, revisitadas mais tarde na maturidade e contraditadas (ou não) por outras personagens vão sendo expostas ao leitor com a sua complexidade ao longo das narrativas. A quebra das relações dos sujeitos com os espaços ou o impedimento de manter as relações almejadas com os espaços desejados geram fraturas e vazios que atormentam as personagens. Isto talvez porque, mais do que arquipélagos, as identidades são constelações no sentido de que são imaginárias, mas, mesmo sendo contrutos mentais, não deixam de ser decisivos para a formação dos seres como a Literatura nos ensina a ver.

\section{NOTAS}

\footnotetext{
1 A expressão aristotélica surge frequentemente traduzida em francês por "agencement des faits", em espanhol encontra-se a expressão "estructuración de los hechos" e em inglês surgem expressões como "structure of incidents" e "arrangement of incidents". Na tradução portuguesa de Eudoro de Sousa, surgem as expressões “composição dos atos" e "trama dos factos" (Aristóteles 1994: 111).

2 Neste sentido as personagens aproximam-se do "rôdeur" (traduzível talvez por "rondista"), um dos três tipos de escritores-caminhantes que Kenneth White distingue: “flâneur", "rôdeur" e "nomade” (White 2016: 72).

3 Jean Bosman vai anotando cada "ponto de referência" no seu "caderno preto" (Modiano 2010: 7). Trata-se de um objeto e, como tal, situado no espaço, mas que ganha a relevância de servir para reconstituir os espaços e os eventos localizados em espaços.
}

N. ${ }^{3} 3$ - 6/ 2018 | 155-171 - ISSN 2183-2242 | http:/dx.doi.org/10.21747/21832242/litcomp38a9 
${ }^{4}$ Muitos exemplos podem ser aduzidos. Assim, logo no início do romance, é a Av. de l’Opéra que o faz recordar Mérovée, um dos colegas do escritório onde trabalhava Margaret; adentrando na narrativa, é ao recordar a sua conversa com Margaret nos jardins de l’Observatoire, quando esta lhe diz que se alojara no Hotel Sévigné, na rue Belloy, que ele se questiona por que razão a não encontrara antes, uma vez que ia com frequência a essa rua para se encontrar com Simone Cordier, que lhe dactilografava os textos (Modiano 2010: 51).

5 Segundo o autor, "foi durante os anos sessenta que o termo imagologia adquiriu o sentido que conhecemos hoje". (Westphal 2016: 234)

60 autor esclarece o contributo trazido por esta abordagem: "Contribuiríamos desse modo para determinar o espaço comum, nascido no/do cruzamento dos diferentes pontos de vista”. (idem, 234)

7 Para o autor, "toda a identidade cultural é só fruto de um trabalho incessante de criação e recriação" (ibidem).

\section{Bibliografia}

Aristóteles (1994), Poética (tradução, prefácio e introdução de Eudoro de Sousa), Lisboa, IN-CM.

Borges Filho, Ozíris (2007), Espaço e Literatura. Introdução à topoanálise. Franca-SP, Ribeirão Gráfica e Editora.

Carvalho, J. Rentes de (2016), A Amante Holandesa, Lisboa, 11-17.

Ingarden, Roman (1979), A obra de Arte Literária, Lisboa, Fundação Calouste Gulbenkian. Gil, Fernando (1996), Tratado da Evidência, (ed. orig. em fr. 1982), Lisboa: IN-CM. 
Gentner, Dedre (1988), "Metaphor as Structure Mapping: The Relation Shift", in Child Development, no 59, pp. 47-59 (cons. em 30-5-2017; disponível em: http://groups.psych.northwestern.edu/gentne r/papers/Gentner88b.pdf ).

Hühn, Peter; Schmid, Wolf; Schönert, Jörg (eds.) (2009), Point of View, Perspective, and Focalization: Modeling Mediation in Narrative, Berlin, Walter de Gruyter.

Modiano, Patrick (2010), L'horizon, Paris, Folio, Editions Gallimard.

Nancy, Jean-Luc (2011), O Peso de um Pensamento, A Aproximação, Lisboa, Palimage.

Phelan, James and Rabinowitz, Peter J. (2012), "Narrative Worlds: Space, Setting, Perspective", in Herman, David et al. Narrative Theory: Core Concepts and Critical Debates, Ohio State University Press, pp. 84-110.

Ryan, Marie-Laure (2014), "Space”, in The Living Handbook of Narratology (cons. em 14-52017; disponível em: http://www.lhn.uni-hamburg.de/article/space).

Ryan, Marie-Laure / Foote, Kenneth / Azaryahu, Maoz (2016), Narrating Space / Spatializing Narrative, Columbus, The Ohio State University Press.

Sheringham Michael (2006), Everyday Life: Theories and Practices from Surrealism to the Present, Oxford: Oxford University Press.

Westphal, Bertrand (2016), "Por uma abordagem geocrítica dos textos — Esboço”, in Filho, Ozíris Borges (org.), O Espaço Literário. Textos Teóricos, Uberaba (MG), Ribeirão Gráfica Editora, pp. 211-242.

White, Kenneth (2016), “Contre la cacotopie. Tactique urbaine, stratégie métropolitaine”, in Amar, Georges; Bouvet, Rachel et Loubes, Jean-Paul (dir.), Ville et géopoétique, Paris, L'Harmattan, pp. 63-76. 
Maria João Simões é docente da Faculdade de Letras da Universidade de Coimbra, onde leciona Literatura e Cultura Portuguesas Contemporâneas. Apresentou a dissertação de doutoramento Ideias Estéticas em Eça de Queirós, em 2000. Integra a Comissão Executiva do CLP - Centro de Literatura Portuguesa, no âmbito do qual coordenou as seguintes publicações: O Grotesco (2005), O Fantástico (2007), Imagotipos Literários: Processos de (Des)Configuração na Imagologia Literária (2011), Impressões Surreais. O Surrealismo entre Surrealismos Europeus (2015). Coordena atualmente o projeto interno "Literatura, Imagologia e Transnacionalismo: Representação de Migrações". Selecção de artigos publicados: "Imagology and Relational Complexity: The Group Stereotype" in Coutinho, E. (ed.), Beyond Binarisms. Discontinuities and Displa-cements: Studies in Comparative Literature, Rio de Janeiro, Aeroplano Editora, 2009; “Novos Veios da Literatura Comparada: Imagologia e estereótipos”, in Cumplicidades Comparatistas, Univ. do Minho, 2009-2010. Em co-edição: Lourenço, A.; Santana, Mํㅡㄹ.; Simões, Mạ João (coord.) O Século do Romance. Realismo e Naturalismo na Ficção Oitocentista, Coimbra, Centro de Literatura Portuguesa, 2013; Reis, Carlos; Simões, Maria João; Fialho, I. (orgs da edição crítica de) Queirós, Eça de $A$ Correspondência de Fradique Mendes. Memórias e Notas, Lisboa, IN-CM, 2014. 